\title{
House stock forecasting based on population growth. A case of Nur-Sultan City, Kazakhstan
}

\author{
Timur Zhussupov, iD Lazzat Yelubay \\ Department of Structural Engineering, L.N. Gumilyov Eurasian National University, 010008, Satpayev str., 2, Nur- \\ Sultan, Kazakhstan \\ *Correspondence: timurvictorovich@gmail.com
}

\begin{abstract}
Since the beginning of 2020, the "Nurly Zher" housing and communal development program for 2020-2025 came into force in Kazakhstan. Within the framework of this program there are tasks of capital repair and renovation of the housing stock. The passportization of the housing stock was adopted as one of the measures to solve this problem. At the same time there are some discrepancies in the statistical data between the Committee of Statistics of the Ministry of National Economy of the RK and Local Executive Authorities with a simultaneous increase in the volume of housing construction. This article examines the volume of residential buildings commissioned in Nur-Sultan depending on changes in the population of the city. It is assumed that as the number of people in the city will increase the volume of housing stock. To understand the volume of housing in Nur-Sultan in the period of the program "Nurly Zher" in the article gives a forecast increase in commissioned housing by $62 \%$ by 2025 , compared with the value at the end of 2020 . Based on the data obtained it is concluded that for a more effective solution to the problem of capital repair and renovation of housing stock an alternative approach or tool is needed.
\end{abstract}

Keywords: model for forecasting, housing stock, renovation of dilapidated housing, complete overhaul, housing programs.

\section{Introduction}

Over the past few years, various government documents of the Republic of Kazakhstan (RK) addressed the issue of housing. In particular, in the message of the Head of State to the people of Kazakhstan on October 5, 2018 it was mentioned the need to build rental housing for socially vulnerable populations [1]. On September 2, 2019, the Nationwide Action Plan on the implementation of the Address of the Head of State to the People of Kazakhstan [2] included the issue of allocation of budgetary credits for the modernization and repair of the housing stock of Kazakhstan. These and other documents can be attributed to the prerequisites for the development of the housing and communal development program "Nurly zher" for 2020-2025. This program was approved by the decree On Approval of the State Program of Housing and Communal Development "Nurly Zher" for 2020-2025 (hereinafter - the Program), which came into force on 1 January 2020 [3]. The program is a logical continuation of the previous State program of housing "Nurly Zher", adopted on June 22, 2018 [4]. The program is aimed at combining measures of state support in matters of housing construction, provision of housing for citizens, modernization and development. The document states that "the unified housing and housing and communal policy will provide a comprehensive approach to the development of a comfortable living environment of settlements, taking into account the trends of urbanization, population growth" of the housing and communal system. 
It is especially worth highlighting one of the tasks of the Program "Capital repair and renovation of the housing stock", for the implementation of which the following indicators are supposed to be measured for the period of the Program:

- Number of repaired apartment buildings - measured in units.

- Coverage of the assessment of the technical condition of the housing stock - measured as a percentage.

As measures to solve this problem, the Program adopted:

- Passportization of the housing stock;

- Overhaul of the repaired apartment buildings;

- Promotion of energy saving in the sphere of housing and communal services;

- Renovation of the housing stock.

Passportization is understood here as the so-called inventory of the repaired apartment buildings, which will collect data and form a register of the number of houses with their technical characteristics and equipment. On the basis of this data emergency housing will be identified, subject to demolition or major repairs.

As regards the renovation of the housing stock it is envisaged to comprehensively reconstruct the "old" neighbourhoods of the cities through the demolition of emergency (dilapidated) housing. The objects subject to renovation will be determined on the basis of the wear and tear of the building structures and their compliance with the operational requirements for each individual building.

However, the same document in the SWOT analysis (or SWOT matrix, where S - strengths, $\mathrm{W}$ - weaknesses, O - opportunities, T - threats) in the factors "Weaknesses" highlighted item "Discrepancy data on the number of housing between the Committee of Statistics of the Ministry of National Economy of Kazakhstan and the Local Executive Bodies", while the factors "Strengths" has a point "Continuous growth in housing construction and public financing" [3].

Considering the trend of the development of Nur-Sultan, it is impossible not to pay attention to the growth of the population. In the period from 1998 to 2020, the population grew from 326.9 thousand people to 1.18 million people (data are taken at the end of the period), that is, the number of people living in the capital, increased by more than 3.5 times over the past 23 years (Figure 1) [5].

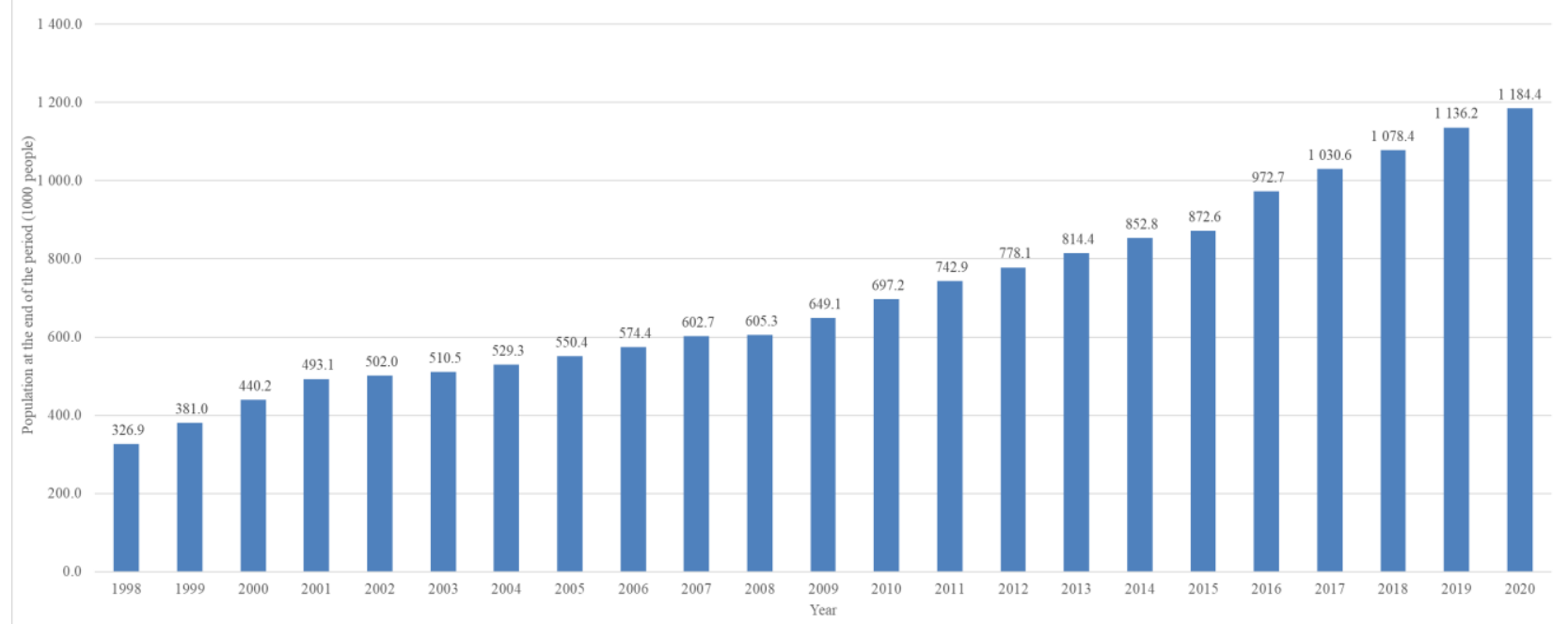

Figure 1 - Population of Nur-Sultan at the end of the period, thousand people

In addition, a similar situation is noticeable in social security during the same period [5]:

- the number of hospital organizations increased from 15 to 37 units (almost 2.5 times);

- the number of schools increased from 48 to 133 units (more than 2.5 times);

- the number of higher educational institutions increased from 7 to 15 units (more than 2,5 times). 
One of the target indicators of the Program is to increase the annual volume of housing commissioned and the provision of housing - $26 \mathrm{~m} 2$ per resident. In 2020, a total of 15.3 million $\mathrm{m}^{2}$ of housing was commissioned across Kazakhstan, of which 3 million m 2 was built only in the city of Nur-Sultan. At the same time, the total area of the housing stock in 2020 was $24,300,700 \mathrm{~m}^{2}$. If we consider the period from 1998 to 2020, there is also a positive trend of growth in the volume of housing (Figure 2) [5]. It is noteworthy that this volume increased by 22.5 times.

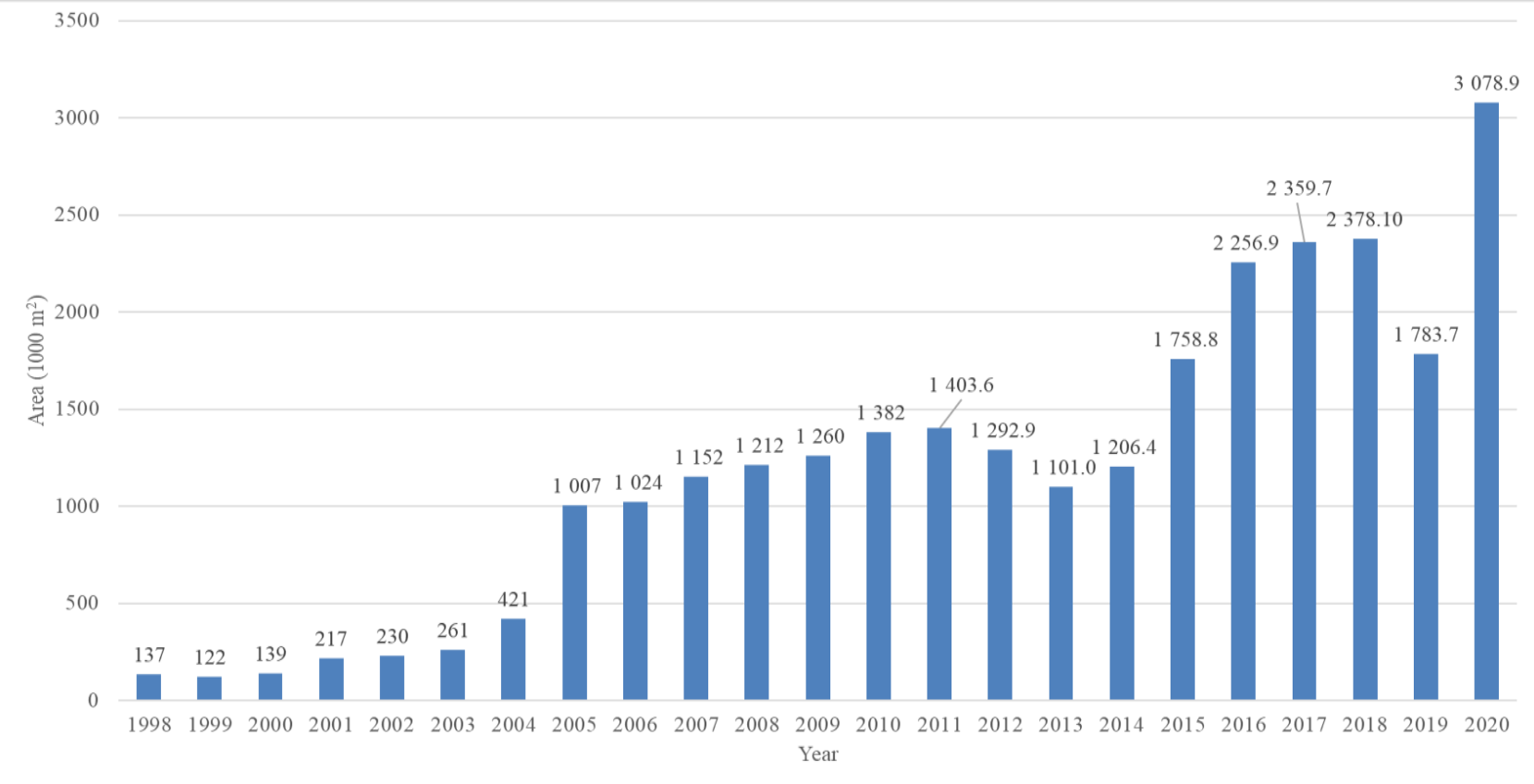

Figure 2 - Commissioning of residential buildings in Nur-Sultan, thousand $\mathrm{m}^{2}$

Provision of the population with housing in Nur-Sultan during the period from 1998 to 2020 increased by 1.7 times from $17.5 \mathrm{~m}^{2}$ to $30.5 \mathrm{~m}^{2}$ [5], which means that in 2020 provision of the population with housing in the capital exceeded the target national value by $4.5 \mathrm{~m}^{2}$. From all the above it is possible to trace the regularity of growth of the population with the growth of commissioned residential buildings and growth of provision of the population with housing.

In order to implement the Program and fulfil one of its objectives "Capital repairs and renovation of the housing stock" it is necessary to understand the current size of the housing stock and in addition it is necessary to have an idea of its further development during the program implementation period (2020-2025).

The purpose of this article is to analyze and forecast statistical data on the volume of the NurSultan real estate fund on the basis of data from the Bureau of National Statistics of the Agency for Strategic Planning and Reforms of Kazakhstan [5-7].

\section{Methods}

As part of the analysis of the housing stock of the city of Nur-Sultan compared 2 indicators, namely the total area of annually commissioned residential buildings and the population of the city at the end of the period. Graphs of changes in these two indicators for the period from 1998 to 2020 were constructed. In this graph on the x-axis indicated years, and the y-axis values of the number in thousand people and area in thousand square meters (Figure 3).

In order to predict changes in the indicators we need, we used the method of approximation, in which the so-called trend line is constructed. There are various parameters for constructing a trend line: exponential, linear, logarithmic, polynomial and power. All of them are based on forming equations with a certain value of approximation reliability $-\mathrm{R}^{2}$. This number is the coefficient of 
determination of the equation of the trend line and shows how close the values of the trend line are to the actual data. The closer this value is to 1, the more reliable the trend line is.

After determining the equation of the trend line, $\mathrm{y}$ is calculated by substituting instead of $\mathrm{x}$ the following values after the period in question.

In this paper, we first determined the trend line for the graph of the population against the graph of the area of residential buildings put into service. In determining a more accurate trend line, polynomial trend lines of degree $2,3,4,5$ and 6 were analyzed to obtain more reliable data. It was the polynomial trend line that had the $\mathrm{R}^{2}$ value closest to 1 .

After the obtained values of the number for each degree were compared with the current value on November 1, 2021 from the database of the Bureau of National Statistics of the Agency for Strategic Planning and Reforms of the Republic of Kazakhstan. Thus, the closest to reality trend line was selected and the forecast of population change until 2025 was formed.

Next, we plotted the change in the area of residential buildings commissioned in relation to the change in the population, where along the $\mathrm{x}$-axis we took the values of the population and along the y-axis - the values of the area.

Then, by analogy with the population projection, a trend line was determined for the area of commissioned residential buildings, and then the projected values up to 2025 were calculated, where the projected population values were substituted for the $\mathrm{x}$ values in the resulting trend line equation.

\section{Results and Discussion}

The graph below (Figure 3) shows the changes in the two indicators in question from 1998 to 2020. As can be seen, the annual increase in the area of residential buildings commissioned is accompanied by a positive increase in the population. From this we can assume that the total area of housing commissioned depends on the population.

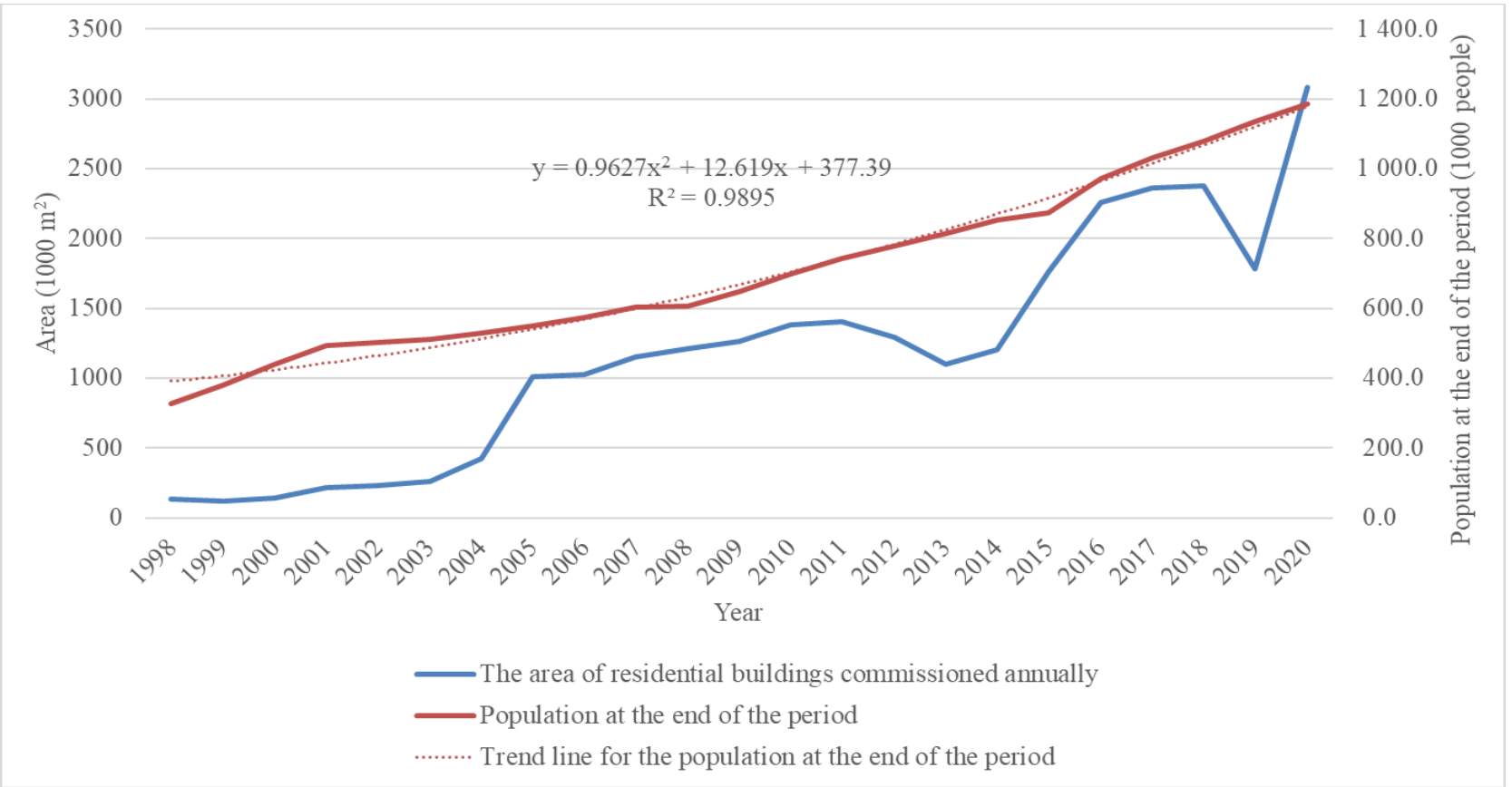

Figure 3 - Relationship between the total area of commissioned residential buildings and population in Nur-Sultan 1998-2020

Figure 3 also shows the forecast of population growth over the next 5 years using a trend line.

In this case, a polynomial trend line of degree 2 was chosen for the population indicator and equation 1 was defined for it: 


$$
y=0,9627 x^{2}+12,619 x+377,39
$$

where $\mathrm{R}^{2}=0.9895$, at which the prediction results were as close to reality as possible, taking into account the data at the time of writing.

Further, to calculate the projected values of the indicator for the next 5 years, the values of periods are substituted into the obtained equation, where 1998 is period 1,2021 is period $24(x=24)$, 2022 is period 25 ( $x=25)$, etc. The obtained results of the population forecast are shown in Table 1.

Table 1 - Population Forecast Nur-Sultan 2021-2025

\begin{tabular}{cccccc}
\hline \multirow{2}{*}{ Indicators } & \multicolumn{5}{c}{ The Year } \\
\cline { 2 - 6 } & 2021 & 2022 & 2023 & 2024 & 2025 \\
\hline Population, thousand people & 1234,8 & 1294,6 & 1356,3 & 1419,9 & 1485,5 \\
\hline
\end{tabular}

Now consider the dependence of the total area of housing commissioned on the population indicator. Figure 4 shows the resulting graph.

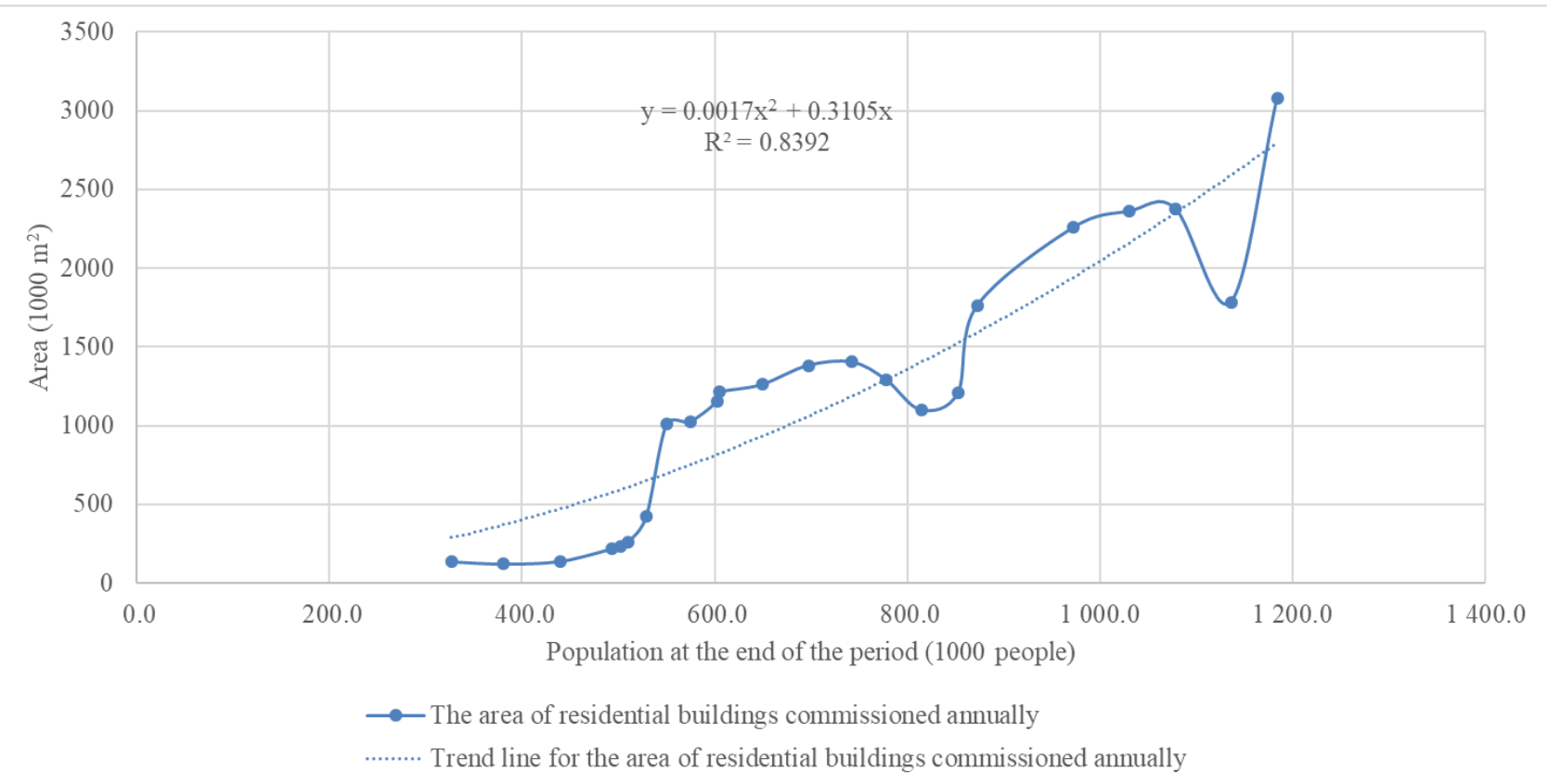

Figure 4 - The total area of commissioned residential buildings depending on changes in the population

The resulting trend line for the total area of commissioned residential buildings is described by equation 2 :

$$
y=0,0017 x^{2}+0,3105 x
$$

where $\mathrm{R}^{2}=0.8392$, at which the results of the forecast were as close to reality, taking into account the data at the time of writing.

Using the resulting equation, we calculated the projected values of the total area of housing to be commissioned, see Table 2 .

Table 2 - Forecast of the total area of commissioned residential buildings in Nur-Sultan for 20212025

\begin{tabular}{cccccc}
\hline \multirow{2}{*}{ Indicators } & \multicolumn{5}{c}{ The Year } \\
\cline { 2 - 6 } & 2021 & 2022 & 2023 & 2024 & 2025 \\
\hline $\begin{array}{c}\text { Commissioning of residential } \\
\text { buildings, thous. } \mathrm{m}^{2}\end{array}$ & 2975,3 & 3250,9 & 3548,2 & 3868,3 & 4212,5 \\
\hline
\end{tabular}


As can be seen from the forecast increase in the area of annually commissioned residential buildings will continue with the growth of the population in Nur-Sultan (Table 1, Table 2). Already by 2025 , with a population of almost 1.5 million people, the volume of commissioned residential buildings will reach 4.2 million $\mathrm{m}^{2}$ per year. This is $37 \%$ higher than in 2020 . At the same time, the total volume of housing stock by 2025 is expected to increase by 17.8 million $\mathrm{m}^{2}$.

\section{Conclusions}

Returning to the task "Capital repair and renovation of the housing stock" of the Program, the forecast clearly shows that every year the volume of housing fund of Nur-Sultan will grow. Taking into consideration that in 2020 there were 24300,7 thousand $\mathrm{m}^{2}$ of the total floor area of the housing stock in the city and in the next 5 years the projected increase is 17855,3 thousand $\mathrm{m}^{2}$, that is the housing stock will increase by $73 \%$. Such increase in the volume of housing stock will have a significant impact on the solution of this problem.

Taking into account all of the above there is a need to form a more effective approach to the issue of capital repair and renovation of housing stock

The results of this analysis will be used in the work to create a tool that will be used to facilitate decision-making on the demolition or reconstruction of dilapidated housing in Nur-Sultan.

\section{References}

1. State of the Nation Address of President of the Republic of Kazakhstan Nursultan Nazarbayev, October 5, 2018 Official website of the President of the Republic of Kazakhstan [Electronic resource] // Akorda.kz. — Mode of access: https://www.akorda.kz/en/addresses/addresses_of_president/state-of-the-nation-address-of-president-of-therepublic-of-kazakhstan-nursultan-nazarbayev-october-5-2018 (accessed date: 11.12.2021).

2. Presidential Decree No. 152 of September 10, 2019. - 2019.

3. Decree No. 1054 of the Government of the Republic of Kazakhstan dated December 31, 2019. — 2019.

4. Decree of the Government of the Republic of Kazakhstan No. 372 of June 22, 2018. - 2018.

5. Dynamics of main socio-economic indicators [Electronic resource] — Mode of access: https://stat.gov.kz/region/268012/dynamic (accessed date: 11.12.2021).

6. Express information about the change in the population of the city of Nur-Sultan from the beginning of 2021 to November $1, \quad 2021 \quad$ [Electronic resource] - Mode of access: https://stat.gov.kz/region/268012/statistical_information/industry/7161 (accessed date: 11.12.2021).

7. Investment and construction statistics. On the performance of construction works and commissioning of facilities in the city of Nur-Sultan. 6 series. January-October 2021 [Electronic resource] — Mode of access: https://stat.gov.kz/region/268012/statistical_information/industry/71162 (accessed date: 11.12.2021).

\section{Information about authors:}

Timur Zhussupov - PhD Student, Department of Structural Engineering, L.N. Gumilyov Eurasian National University, Nur-Sultan, Kazakhstan, timurvictorovich@gmail.com Lazzat Yelubay - MSc Student, Department of Structural Engineering, L.N. Gumilyov Eurasian National University, Nur-Sultan, Kazakhstan, lyazzat.elubay@mail.ru 